\title{
Modern Creative Expression of Chinese Traditional Graphic "Cattle" — Taking the Visual Design of Idioms as an Example
}

\author{
Danyang $\mathrm{Zhu}^{1, *}$ Yifan Wang ${ }^{1}$ \\ ${ }^{1}$ College of Art and Design, Wuhan Textile University, Wuhan, Hubei, China \\ *Corresponding author. Email: 994240916@qq.com
}

\begin{abstract}
The cattle have played a very important role in ancient Chinese agricultural production and social life. They have a mild temperament and are a representative of hard work. For thousands of years, the cattle culture has been running through the soul and blood of the Chinese nation. As a special symbol representing the Chinese nation, the Niu (cattle) Spirit has always entrusted people's good expectations for life, contains the rich cultural connotation and profound cultural heritage of the Chinese nation, and is a valuable asset of Eastern culture. [1] Idioms have shown the wisdom and expressive ability of the Chinese people in the long history of the five thousand years of Chinese civilization. As an important carrier of cultural heritage, the idiom itself is a fixed term with a balanced and neat form, complete and condensed meaning. Graphics and idioms are two different types of symbolic attributes. As important carriers for recording and transmitting information, they have unique cultural connotations and artistic beauty. The unique artistry of idioms provides many new design ideas and methods for modern graphic design. This article takes the style and characteristics of traditional Chinese "cattle" graphics and the innovative combination of idiom visualization graphics design as the research goal, and analyzes and discusses the perfect combination and innovative application of the two in the current era, to rejuvenate the modern visual expression based on the visualization and innovative design of traditional graphics.
\end{abstract}

Keywords: Chinese traditional graphics, "Cattle" graphics, Idioms, Visual design.

\section{INTRODUCTION}

\subsection{Subject Background}

Chinese culture with a long history has gradually formed unique oriental patterns and ornamentations during the long historical evolution, including various forms of traditional Chinese patterns such as character patterns, animal and plant patterns, and tribal totems. [2] The traditional "cattle" graphic reflects the splendid traditional Chinese culture. The graphic is intended to have a strong Chinese farming civilization. In fact, the "cattle" graphic is deeply influenced by traditional Chinese culture at the same time. It conveys the breath of traditional culture, which not only has its own symbolic meaning, but also has its unique compositional beauty. [3]
Idioms are regarded as a shining pearl of Chinese culture. They have always been favored and used by Chinese people for the rigorous structure, simple form, deep connotation, and strong expressive power. An idiom expresses a certain positive meaning and has the functions of warning, encouragement, reminder, enlightenment, etc. After being refined by the long history, they have strong vitality and appeal. [4] It is necessary to incorporate the connotation of idioms into the modern creative design of Chinese traditional "cattle" graphics, and promote the development of graphic design in an innovative form.

\subsection{Research Purpose and Significance}

This article attempts to take the Chinese traditional "cattle" graphics and the visual design of idioms as clues and combine the two, and carry out research on the related issues of the modern 
creative expression of the "cattle" graphics. Drawing lessons from folklore, fine arts, design and other theories and related research results as theoretical support, the researchers explore the contemporary creative expression in traditional Chinese "cattle" graphics.

Corresponding idioms can express their forms more abundantly through visual graphic design, and optimize visual effects through modern redesign of graphics, allowing audiences to transcend information limited by different languages and cultures. At the same time, the graphic design of idioms is a display of the connotation of visual form in contemporary design, and the form of semantic expression is more intuitive and faster to convey information, which is also the inheritance and development of the visual art form.

\section{OVERVIEW OF CHINESE TRADITIONAL "CATTLE" GRAPHICS}

\subsection{The Connotation of Traditional Chinese "Cattle" Graphics}

In ancient China, the cattle were a symbol of hard work, bravery, stubbornness, and selfless dedication. In the early days of human social life, the cattle had profound social, ritual and religious significance. After thousands of years of historical and cultural accumulation, cattle occupy an extremely important position in the minds of the Chinese nation. [5] Traditional Chinese folk art with the "cattle" graphic as the main theme has a rich variety of expressions and contains rich spiritual meanings.

With the later development and progress of ancient Chinese farming techniques, the cattle went from the early sacrifices of the ancestral temple to an important means of transportation into the countryside. During the Spring and Autumn Period, the allusion that Confucius led students to travel around various vassal states in cattle carts to the people is well known. During the Wei, Jin and Southern and Northern Dynasties, cattle were born slowly and walked steadily. Ox carts were sought after by the gentry for their comfortable and decent way of traveling and affordable prices. Therefore, traveling in Ox carts was a symbol of status, scholar-officials "won't travel by horses", pottery ox carts and portrait tiles fully reflect the ancient Chinese's love and emphasis on ox carts ("Figure $1 ")$.

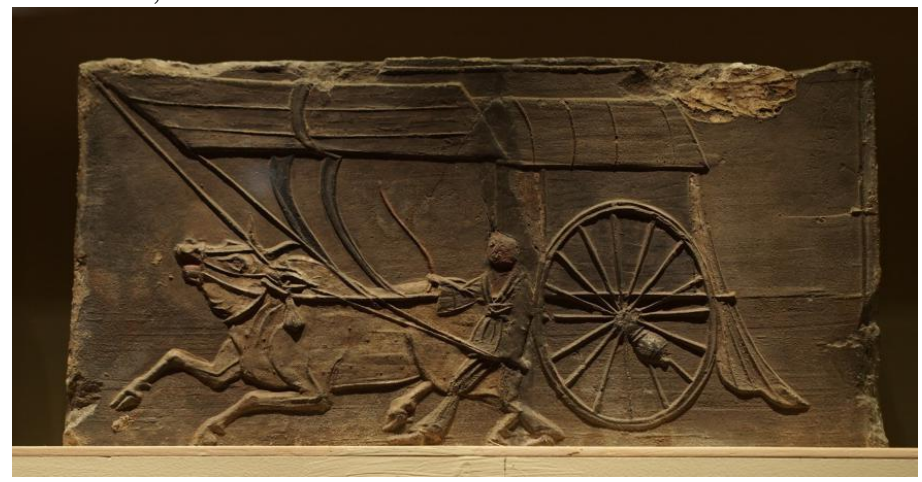

Figure 1 The Southern Dynasty Ox Cart Portrait Brick.
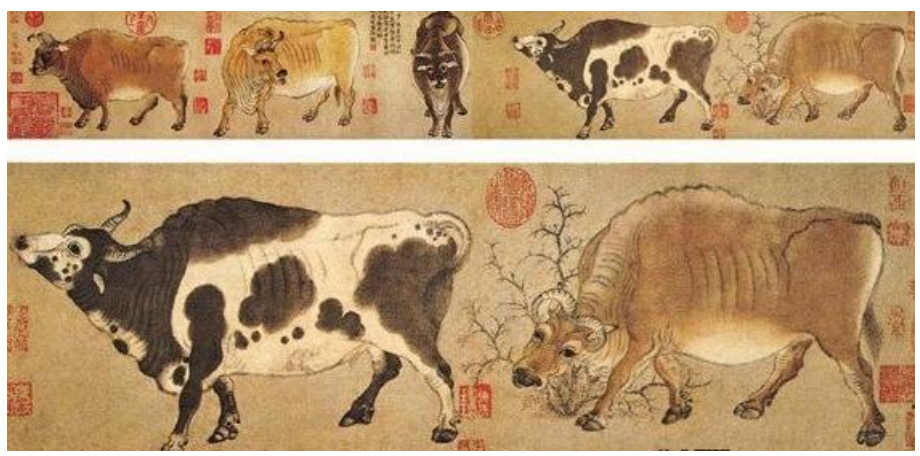

Figure 2 "Five Bulls". 
In China, which has a profound agricultural culture, cattle have always played an important role, and the ancients often portrayed these hard-working and dedicated domestic animals in their pastoral paintings. Among them, the classical Chinese painting "Five Bulls" painted by Tang Dynasty painter Han Huang is the most famous (see "Figure $2 ")$. In the painting, five bulls with different images and different postures are lined up, which contains the auspicious meaning of "five blessings at the door". It can be seen from this that the ancient art works related to "cattle" fully reflect the important position of the cattle.

\subsection{Chinese Traditional "Cattle" Graphic Performance Characteristics}

The traditional "cattle" graphics are rich in layers and delicate, bright and full of colors, which can vividly interpret the spiritual connotation of being down-to-earth and daring to fight.("Figure 3") Chinese artists are keen to portray the cattle into a majestic, powerful and invincible image of a running bull. The running bull's eyes are piercing, the head is upright, and the four hooves are powerful, showing the spirit of forging ahead, fearlessness, and hard work. [6] In addition, the warm and affectionate scenes of cows and cubs licking their calves are also common themes, conveying good wishes for family prosperity and harmony and reunion.

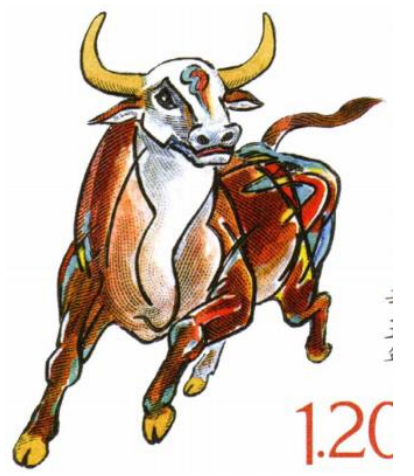

Figure 3 "The Year of the Xin Chou Bull" — Wang Huming.

\section{IDIOM VISUAL DESIGN OF CHINESE TRADITIONAL "CATTLE" GRAPHICS}

\subsection{Idiom Visual Design Concept}

Based on the humanistic connotation carried by Chinese idioms, it refines and presents visual symbols that can be transformed. Using the currently popular media as a carrier, various visual elements and visual expressions are used to artistically design idioms, and then convey the connotation and design ideas of idioms to people more intuitively and clearly, and shorten the distance between people and Chinese culture.

\subsection{Ability to Be Possessed in the Visual Design of Idioms}

The Chinese culture is broad and profound, and the four-character idioms with clear and clear syllables are the soul and essence of Chinese culture. Specifically, the four-character idiom is concise and simple, with insightful connotations, capable of summarizing and expressing a vivid story ingeniously and completely, which is thoughtprovoking and intriguing. [7] Expressing the idiom through different forms and techniques can make it more interesting and understandable. Then, the graphical design of idioms requires the following capabilities:

The first is the knowledge and understanding of idioms. The visual design of idioms must first have a deep understanding and thoroughness of the meaning of the idiom, and only by grasping the meaning of the idiom can it be better transformed into the meaning of the idiom.

The second is the modeling ability. A good grasp of modeling ability is the basis for the visualization of "cattle" graphics. In this process, it is required to create an image with rich connotation, a sense of form and overall effect. The performance must be summarized, refined, and accurate.

The third is the color ability. The visual control of color is mainly embodied in the ability to observe and understand color, the ability to master color principles, and the ability to generalize and express colors. It is a must to master color-related knowledge and color shaping ability.

The forth is the creative thinking ability. Visual design is often applied to graphic elements in order to achieve visual presentation effects. Among them, creativity is more valued, so designers should have the ability of creative thinking.

Only when the above foundations are laid, the visual design of idioms can be created. 


\section{CREATIVE DESIGN AND APPLICATION OF "CATTLE" GRAPHICS}

\subsection{Design Principles}

After a long period of evolution, the traditional "cattle" graphic elements with primitive farming civilization and the culture behind cattle may not be able to adapt to the demands of contemporary aesthetics, so the traditional "cattle" graphic elements must be combined with an abstraction from the perspective of secondary transformation when carrying out modern creative expressions with idioms, and carry out the "re-creation" and "secondary abstraction" of traditional "cattle" graphic elements and modern creative expressions to enable the innovative combination of traditional culture and graphic art.

In the mid-term, the visual design of the "cattle" graphic as an idiom is not an arbitrary and unconstrained idea, but to follow three principles:

\subsubsection{Unity}

Idioms are a kind of condensing of traditional Chinese language and culture, and their connotations are incisive, equivalent to a minisentence. When designing, designers need to pay attention to the harmony and unity of the idiom's connotation and its expression form, artistic style and overall effect.

\subsubsection{Artistry}

The ultimate goal of the visual design of idioms is to express the idioms in an artistic way. The aesthetics in form achieves artistic effects through elements such as contrast and harmony, rhythm and melody, symmetry and balance. [8] At the same time, idioms and graphics must be fully endowed with unique personality characteristics, so that they can become a truly vivid art.

\subsubsection{Being Easy to Understand}

When making artistic creation, it is very necessary to strictly follow the idiom's easy to understand. A good design is based on the easy-tounderstand basis, otherwise it will cause information transmission barriers and violate the original intention of the design.

\subsection{Creativity and Performance Methods}

\subsubsection{Reproduction of Traditional Elements}

Traditional cultural elements reflect the results of the long-term evolution of human history and culture. Modern design works can only be classics if they have national cultural heritage, which transforms traditional paintings or graphic elements related to "cattle" into modern creative forms, while the essence of the work is to restore traditional elements. Combining traditional graphic elements with emerging aesthetic trends, people will involuntarily think about the changes of the times and the collision of cultures. [9]

\subsubsection{Remodeling of Traditional Graphics}

Introducing traditional elements into modern creative design and reflecting a brand new visual effect, the new shape created is more pioneering. Through the use of many abstract symbols and traditional patterns, traditional graphic elements are artistically processed and applied in modern creative expression.

\subsubsection{The Reconstruction of Abstract Symbols}

Abstract symbols are abstracted from the core of traditional graphic elements. Symbols and plastic art are connected with each other. Symbols refer to artistic elements with appearance characteristics, and are some simple patterns expressed by lines and colors. Many contemporary abstract symbols are the simplification and refinement of traditional graphic elements, combining traditional elements with modern aesthetics in creative design, in order to retain their traditional style features and distinctive style.

\section{3 "Cattle" Creative Graphics That Visualize Idioms}

The visual graphic design of idioms is to create a graphic that has formal beauty and can reflect its spiritual connotation according to the meaning of the idiom itself. [10] The graphic design of idioms needs to be based on graphic creativity. When designing the "cattle" graphic, the "cattle" symbol can be used as the starting point to visually and intuitively express the meaning of the idiom. 
For example, "Monsters and demons" ("Figure 4") refers to the Minotaurs and Snake Gods, describing the illusory and grotesque or various bad guys in the work. The visual expression of this idiom can be creative to combine the graphics of the bull and the snake, and at the same time, some visual elements of ghosts and bones are added to set off a psychedelic and grotesque atmosphere.

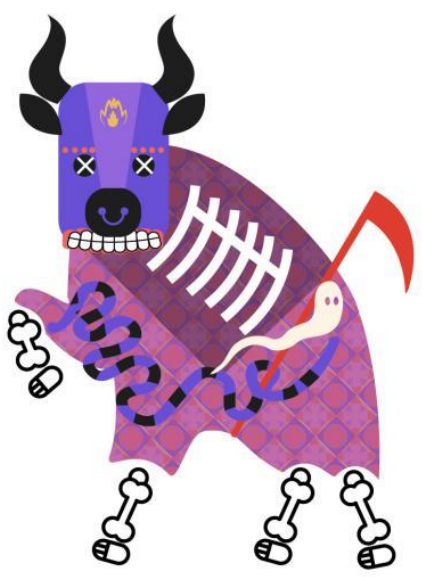

Figure 4 Monsters and demons.

"Playing the piano against the bull" ("Figure 5") mainly tells the story of Gongming Yi playing music for the bull during the Warring States Period. The visual design of this idiom starts from the perspective of the core connotation of the idiom, and uses a large number of graphic symbols representing music to interpret its connotation: the designer replaces the bull's head with a guitar panel, and the bull's horns are composed of notes and staves. The designer replaces the body with piano keys, rhythmic geometric shapes and line elements, and use aesthetic principles to process the graphics, so that the overall appearance of the graphics can achieve a harmonious and unified visual effect. In this way, it is easier to understand and full of humor to convey "playing the piano to the bull".

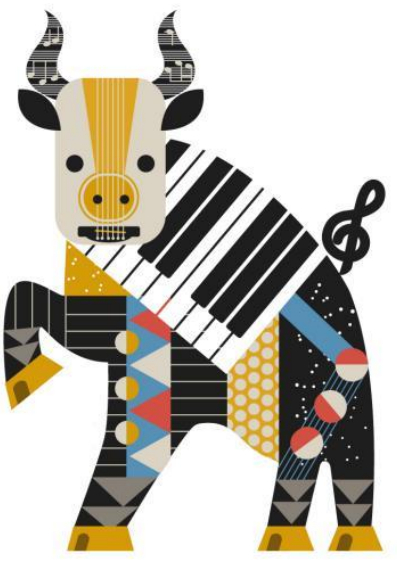

Figure 5 Playing the piano against the bull.

"Rhino looking at the moon" ("Figure 6") means that the horns grow in front of the eyes, and the line of sight is affected by the horns. The angle of the line of sight is almost curved, and the moon is also curved. The full moon is broken up and reconstructed through art expression techniques such as splicing and deconstruction, using simple geometric color patches to express and express the connotation of the idiom.

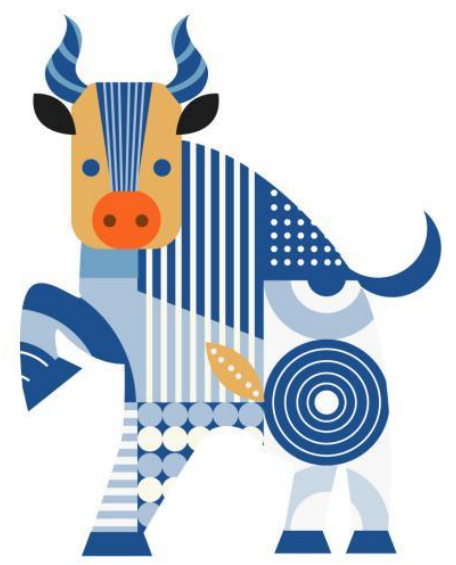

Figure 6 Rhino looking at the moon.

Chinese traditional "cattle" graphics can not only express its brand-new form through the visual design of idioms, but also make the modernized design graphics itself not lose its cultural connotation. The pursuit of beauty in modern design is endless. Traditional graphics, as one of the important elements in modern visual design, pay attention to the cognition and embodiment of cultural connotation in its design. One of the most direct ways to obtain and explore the cultural connotation of traditional graphics and discover its conveying value is to show the cultural connotation 
of idioms in a new form after the aesthetic processing of modern culture, through the appearance and meaning of traditional graphics to shape modern design, so as to continue the connotation of traditional graphics.

\section{CONCLUSION}

The times are constantly evolving, and the charm of traditional Chinese graphic art should be better reflected in the current global diversified new era. When studying the graphic characteristics of idioms, the inner meaning of the semantic relationship of idioms is deeply connected with the external visual performance effect. In the attitude of paying tribute to the tradition and learning, creating new ways of expression, in fact, has a more profound and long-term significance for the development of graphic design of idioms. The graphic design of idioms conveys more comprehensive information and humanistic emotions to the audience through different angles and fields, making this way of transmission more memorable, strengthening the visual effect, shortening the distance between the work and the recipient, and making the memory deep.

Idioms and traditional graphics are interrelated and restrict each other. The semantic expression of idioms reflects the profound sense of history, which makes the graphic design of idioms active in modern design, and fully shows people the humanistic and historical meaning behind the graphics. Of course, the above is just a beginning. How to innovate and promote the graphic design of idioms is now the primary goal. While analyzing and solving problems, it is necessary to pay attention to the symbolism and timeliness of the idioms themselves, as well as the degree of recognition of them. It is also necessary to reasonably use modern graphic design to promote people's sense of identity with local national culture, spiritual culture and material culture.

\section{AUTHORS' CONTRIBUTIONS}

Yifan Wang designed the method and sorted out the data. Danyang Zhu visualized the experimental results and participated in the writing and later modification of the paper.

\section{REFERENCES}

[1] Wang Shouzhi, A History of Modern Design [M]. Beijing: China Youth Publishing Group, 2002. (in Chinese)
[2] Hang Jian, He Jie, Jin Daiqiang, Chinese Traditional Graphics and Modern Visual Design [G]. Shandong Pictorial Publishing House, 2005. (in Chinese)

[3] He Xingliang, Chinese Totem Culture [M]. Beijing: China Social Sciences Press, 1996. (in Chinese)

[4] Lan Chun, Cognitive Linguistics and Metaphor Research [M]. Beijing: Foreign Language Teaching and Research Press, 2005. (in Chinese)

[5] Hou Dongmei, The origin and changes of "cattle culture" $[\mathrm{J}]$. Journal of Henan University of science and technology, 2009. (in Chinese)

[6] People's Fine Arts Publishing House ed., Ox Patient [M]. Beijing: People's Fine Arts Publishing House, 2008. (in Chinese)

[7] Wu Donghai, Restudy of the Chinese "chengyu (成语)" [J]. Journal of Yunnan Normal University(Teaching and Research on Chinese as a Foreign Language), 2012. (in Chinese)

[8] Bai Liping, Graphic research of characters [D]. Hubei: Central China Normal University, 2008. (in Chinese)

[9] Tian Youcheng, Chinese Idioms and Traditional Education [J]. Journal of Yulin University, 2015. (in Chinese)

[10] Hu Miyi, Research on font visual design [J]. Literary life, 2014. (in Chinese) 